\title{
Innovation of the Cultivation Mode of Talents in Animation Education in Colleges and Universities
}

\author{
Yongqiong Zhu \\ School of Wuhan Business University, Wuhan 430056, China; \\ zyqzhuyongqiong@126.com
}

Keywords: animation specialty; talent cultivation mode; movie and TV cartoon

\begin{abstract}
In recent years, animation major of colleges and universities has become the "red card" major by the Ministry of Education. The investigation found that animation graduates are not qualified with poor professional skills, so the market still needs more talents. A lot of animation companies offer well-paid positions for animation designers every year. The talent cultivation of university animation major is seriously out of line with the market. This paper makes a detailed analysis of the current situation of talent cultivation in university animation specialty, then reveals the problems, and finally, introduces the talent cultivation mode innovation by taking the animation experimental class as an example in Wuhan Business University.
\end{abstract}

\section{Introduction}

Since 2009, Chinese government has vigorously supported the animation industry. The animation programs of many universities have mushroomed to develop and have brought up a large number of animation students. However, animation major has become the "red card" major of the Ministry of Education for many years. The so-called "red card" major means to low major employment rate, low employment rate, low monthly income and the deviation of employment satisfaction. After investigation [1], it found that the shortage of qualified animation professionals is a bottleneck for the development of domestic animation enterprises. On the one hand, it is the employment problem of the graduates of animation majors. On the other hand, it is the talent dilemma that animation enterprises are encountering. The cultivation of Chinese animation professionals is seriously out of touch with the market.

\section{Current Situation of Talent Cultivation of Animation Major}

Compared to the actual demand of animation industry, the number of graduates is not seriously overexcesive, but professional skills don't pass, the market is still a lack of talent, a lot of animation companies in well-paid animation designer every year. This paper makes a detailed survey and analysis on the talent cultivation of animation specialty in universities, and summarizes some 
common problems from the aspects of curriculum setting, teachers and cultivation mode.

\subsection{Course setting}

Animation majors belong to the subject of film and television, is a comprehensive discipline, not only including painting, drama, movies, music, literature, etc many art categories, also involves science and technology, is a unique and comprehensive art form that combines art and technology. Most colleges and universities follow the animation production process and set up relevant courses such as pre-stages, mid-stages, and later stages, and the content of the course is relatively simple. In the teaching of painting classes, many universities follow the traditional art teaching mode, and do not distinguish between the teaching content and the film and television subjects. On the other hand, there is a serious problem of setting up courses for someone in Colleges and universities. Animation technology along with the development of science and technology is in rapid development, for example, in ten years before the FLASH is the main two-dimensional animation software, but in recent years, it is basically eliminated. After Effect become mainstream, a lot of middle-aged teachers don't want to update their knowledge structure, and they are still teaching with FLASH, which has seriously deviated from the market.

\subsection{Teachers}

In the higher education, the ability of the teacher determines the development ability of the major. Through the investigation of the professional teachers of universities, the majority of teachers have no practical experience in enterprises. Stronger strength in domestic animation professional teachers in university is the Communication University of China, Beijing Film Academy, Guangzhou Academy of Fine Arts. Most of the other school's animation experience of teachers from the research results of master or doctor's stage in the tutor's studio, and lacks the practical experience and ability of the enterprise. For example, many of the animation teachers in Hubei Academy of Fine Arts were studying traditional Chinese painting. In addition, there is a serious shortage of teachers. The number of students has also risen sharply in recent years, with the release of Chinese university admissions policies. For example, there are 13 teachers in animation majors in Wuhan Business Univesity. The total number of students is about 400, with an average teacher with more than 30 students, and the ratio of teachers and students is seriously exceeding the standard.

\subsection{Cultivation model}

University-enterprise cooperation and Tutor Studio System are the main training modes. The original intention of the cooperation between university and enterprise is to cultivate the students to meet the needs of the industry. At present, most of the cooperation only stays in the primary mode, and there is no further cooperation. It mainly adopts the mode of teaching by the teachers of the industry, but does not take the project type practice teaching to improve the comprehensive quality of the students in an all-round way, so there is still a lot of improvement. Even many cooperate with each other to become a contract, so long as the company has signed a contract with the enterprise, it has established the university-enterprise cooperation, and did not take it into the curriculum. The tutor's studio is the animation production under the guidance of the tutor, but most of the tutor studios in Colleges and universities are just a listing, and the reason is that animation is an art that needs cooperation. One can not make an animation by oneself.

Therefore, from the problems of animation education in Colleges and universities, we can see that it is necessary to optimize the course setting, strengthen the teachers' skill, and promote the 
combination of animation education and animation industry in order to cultivate professional talents who meet the needs of the industry.

\section{Literature References}

Aiming at the talent cultivation of animation specialty, scholars at home and abroad have done a lot of research and put forward many new ideas. In 2014, Lan Luo [2] conducted research and analysis on the talent cultivation mode of the United States, Japan, South Korea and Canada. In 2016, zhang aihua proposed in [3] to cultivate students classification, establish a cultivation mode of "721", will be $70 \%$ of the students to cultivate applied talents, $20 \%$ of the students cultivate inter-disciplinary talent, $10 \%$ of the students into a top research talents. In the same year, in [4] Youtian Ye put forward a progressive teaching reform and cultivation model of talent. In the course, he arranged a year to study the basic language of film and television, the selective painting course (such as sketching, drawing, etc.) supplemented, set up the basic film and television view, and arranged the second year to study the related arts department and improve the visual culture of the film and television style. At the beginning of the course of hearing cultivation, the concept of "audio-visual compatibility" is set up, and then the small, medium and large comprehensive creative courses of animation are arranged for three or four years, and a compound curriculum model of "the whole, the local, the heavy movie and TV cartoon, the convex art" is set up. In 2017, Rui Wang has put forward the course system of "relying on the subject, service industry" development [5], combine animation related to information technology disciplines, such as mobile phone animation, digital media, web design, virtual reality technology, etc... The improvement and enhancement of these advantages courses make the discipline system plumper and keep pace with the times, and also expand the employment opportunities of students.

In 2015, the author took an exchange visit to Bournemouth University, one of the four major universities in animation, to learn about the experience of talent cultivation in Media School of animation major. When the Media School teachers set up their cultivation objectives, they are not built on the basis of a unified outline, but for the industry. It is up to the industry to decide what kind of abilities the students should achieve. They began to understand the needs of the industry through interviews, email and other ways, and then designed the courses according to the industry needs. In the course of designing the curriculum system, according to the advantages of the teachers, they have made clear the combination of art and technology, and have formed distinct characteristics. Unlike traditional animation courses, they do not only teach students to use software to make animation, but also teach students how to design and implement animation in a programming way, which is the most demanding skills in the industry. In the cultivation of students, the mode of tutor system is practiced. They introduce the concept of course units in the curriculum system, and the students choose relevant teachers to guide them according to their own interests and specialty. This will highlight the students' personalized training. In the cooperation of university-enterprise, they choose famous enterprises to cooperate, let the teachers of the enterprise enter the laboratory to guide the students, and lead the students to practice teaching in the way of the project. The whole experimental platform is built exactly the same as the enterprise. In the project, students carry out the team cooperation model, and the students' scores are determined by the enterprise teachers, and only the qualified students can get credit.

By comparing animation education in British universities, it is found that there is a big gap between animation education at home and abroad, which must be innovated in the talent cultivation mode. 


\section{Construction of Talent Cultivation Mode in Animation Experimental Class of Wuhan Business University}

Today, with the expansion of the application of animation, the animation practitioners are required to master the art knowledge , skilled operation technology and innovative thinking, so as to create good animation works with the keen insight and professional height of the animation market. This paper takes the experimental class of animation innovative talents cultivation in Wuhan Business University as an example to illustrate the innovative mode of cultivation applied animation talents.

\subsection{Talent cultivation objectives}

When designing the talent cultivation program, the first question is what kind of talents to train, which is mainly determined by the industry demand, teachers structure and students quality. Wuhan Business University is a comprehensive application-oriented university, students drawing skill is less than that of the professional Academy of Fine Arts, so the design ability and creative ability are not so strong. When positioning the training target, the talent training is positioned as application-oriented talents, which mainly focuses on animation production. Combined with the mainstream 3d animation technology, we cultivate professional talents in 3D animation production.

\subsection{Curriculum system}

In the curriculum system, this experimental class is built for industry-oriented. In order to grasp the direction of the restructure of the curriculum system, the three-dimensional animation production process and tool software are first introduced. In the understanding, the 3D animation process is mainly made of modeling, material, binding, animation, lighting and rendering, and there are corresponding courses setted. In the teaching stage, the basic course of painting in the first grade is set as the main body of drawing human body, rather than the traditional sketch water color. In the first grade, we began to contact audio-visual language and other movie and TV cartoon courses. Next semester, we started the basic teaching of MAYA, so that students could understand the production process of $3 \mathrm{~d}$ animation as soon as possible. The first grade also arranges one weeks of practice, arranges the students to participate in the Hangzhou International Animation Festival, and lets the students contact close with the international front-line animation masters to understand the latest knowledge of animation technology.

The second grade began to learn the basic courses of character design, scene design, story board, animation principle and animation movement axiom. Different from the traditional teaching methods, these courses should be implemented in MAYA, that is to say, the teaching of principles is a part and must be implemented in MAYA.In the course of character design and scene design, students can draw a line draft on paper and then model it in MAYA. The process of coloring is the production process of MAYA materials, with the lighting to make the characters and scenes more realistic. In addition to drawing on paper, the movement axiom also needs to learn the correct adjustment of the animals as well as the human movement axiom in MAYA. In a word, all courses are taught in combination with tool software.

In the third grade, students began to learn composition, special effects courses. We set up practical class at the end of the semester, and let the students to choose the tutor for in-depth study according to their interests. In the next semester, we will carry out university-enterprise cooperation, invite the teachers of the enterprise to come to the class, and lead the students in groups in the form of projects. Finally, the enterprises will grade the students.

In the fourth grade, the students completed the graduation design and submitted the graduation 
piece, job search for the next semester.

The talent cultivation mode of this experimental class has the following characteristics compared with the traditional one.

(1)Targeting clearly, taking software application as the goal, and combining the current mainstream 3d technology to cultivate 3D animation talents.

(2) The combination of principles course and software class will enable students to understand and apply them better.

(3) Carry out school enterprise cooperation in depth and students can grow rapidly in the project.

(4) Rich practical courses can cultivate students' personality and broaden their horizons.

\section{Summary}

This paper, taking the animation experimental class of Wuhan Business University as an example, discusses the innovative mode of animation talents cultivation in colleges and universities, and hopes to provide references for all brothers colleges and universities.

\section{Acknowledgement}

This paper is supported by grant from the Science Research Project of Wuhan Business University(Grant No. 2015KA011).

\section{References}

[1] Yongliang Xiao, Analysis of the current situation of Chinese animation education, Journal of Beijing Union University (Social Science Edition). 2011, pp.71-77.

[2] Lan Luo, An analysis of the training mode of talents in animation education in Colleges and Universities, Popular Culture\& Arts, 2014, pp.216.

[3] Aihuang Zhang, Reform and practice study of animation major's "721" talent training mode-in the Hubei university of technology, Design Education, 2016, pp. 102-103.

[4] Youtian Ye, On the current situation of animation teaching in fine arts colleges and the training mode of progressive talents, Film evaluation,2016, pp. 1-3.

[5] Rui Wang, Research on the Dilemma and the Path Exploration of Animation Talents Training in Universities of Western China, Doctoral thesis of Southwestern University ,2017. 